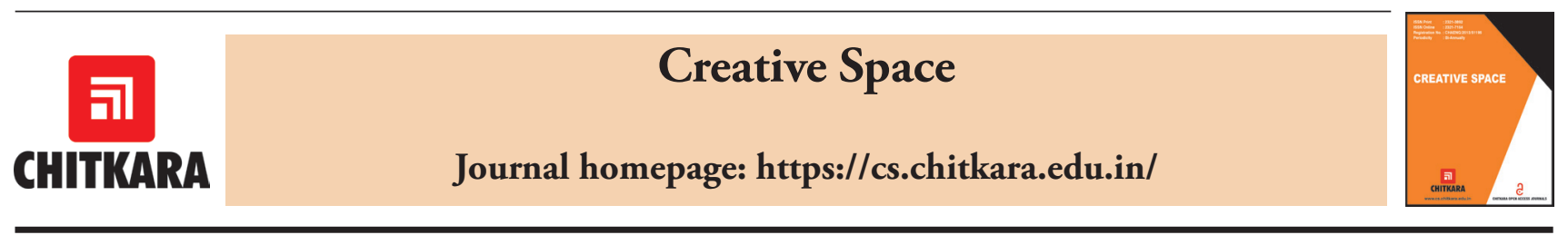

\title{
Spatial Logic of Shopping Malls: Application of Space Syntax in Understanding Economics of Architecture
}

\author{
Sumanta Deb* and Keya Mitra \\ Department of Architecture, Town and Regional Planning, IIEST, Shibpur, West Bengal-711103, India
}

"Email: sumanta04@gmail.com

\section{ARTICLE INFORMATION}

Received: March 11, 2019

Revised: November 24, 2019

Accepted: December 17, 2019

Published online: January 27, 2020

\section{Keywords:}

Bid-Rent Model, Integration, Space Syntax, Tenanting Decision Making

\begin{abstract}
Research findings of architecture and environmental psychology espouse the supremacy of built environment in influencing human behavior in general and movement behavior within buildings and urban areas in particular. Retail management studies on the other hand highlight the importance of influencing human movement as a determining factor for tenant-mix design. Identifying a proper mix of tenant stores in a shopping mall is responsible for its economic performance and is considered a strategic mall management decision. In practice, this decision is taken by management professionals, based mostly on gut feeling or rule of thumb. So, there is a scope for integration of knowledge of these two different disciplines for significantly enhancing tenanting decision making in shopping malls, which will ultimately lead to its economic success. A proper methodology is required in this juncture to relate spatial configuration with movement. Verbal description of space, prevalent in the architectural practice, makes it difficult for correlating with measurable variables like footfall. Space syntax analysis is a potential evidence based approach for quantitative description of configuration in explaining movement through space. The purpose of this paper is twofold: identifying the supremacy of space syntax measures over normal metric measures and establishing a spatial rationale behind tenanting decision making (optimal area and rent of tenant stores) through developing the standard bid-rent model with tenant store specific variables and solving under the conditions of maximizing profit and situation of perfect competition. Consequently, retail space planning will not only be an accommodator of functional requirements but will be a potential tool for economic success through generating, controlling and predicting movement.
\end{abstract}

behaviours, resulting in shops making greater sales. Spatial configuration is therefore a potentially strategic tool that has economic ramifications. However, the economic implications of spatial configuration, per se, have been mostly overlooked in the research literature. Even when spatial configuration has been researched, these configurational studies have been used as case specific diagnostic tools (Brown, 1999) without any generalizable conceptual frame work for widespread applications. Brown (1999) and Roulac (1996) have acknowledged the importance of configuration in, for example, in sharpening real estate decisions but the application of 'architectural economics' has been confined mostly to its cost implications, externalities (Piatkowska, 2012) and also to the influence of aesthetic quality (Vandell \& Lane, 1989). Traditionally, design professionals and real estate decision makers operate in different worlds, with differing approaches, and little scope for integration. 
A shopping mall can be defined as an assemblage of different tenant stores with a central administration. A shopping mall, it has been argued, is an abstraction of an urban setting in an enclosed space that "recreates the urban buzz" removed from the "city streets". Researchers like Carter \& Allen (2012) and Sim \& Way (1989), who have considered shopping malls as miniature urban settings, used a geographical economic theory called the bid-rent theory in explaining the tenant mix therein. The objective of the mall developer is to maximize the earning from the tenant stores while that of individual tenant stores is to maximize their individual profits. These simultaneous objectives are met through tenanting decision making which includes area and rental allocations of individual stores and their exact spatial location and is responsible for the economic performance as explained by Garg \& Steyn (2015) and Kyriaziz \& Cloete (2018). These decisions are essentially spatial (Brown, 1999; Roulac, 1996) but are taken mostly on gut feeling or rule of thumb by management professionals (YimYiu \& $\mathrm{Xu}, 2012$ )-by and large overlooking the designer's perspective. The designer's scope is limited to the design of an aesthetically pleasant spatial envelope that will ultimately house the mix of stores (in terms of area and location) as decided by real estate professionals. In practice, tenant-mix design starts after and on the basis of the architectural design. A shopping mall is therefore an ideal laboratory to explore the economic performance of the spatial arrangement through tenanting decision making.

\section{Review of Literature}

Studies on retail have paid little attention to the microlevel spatial aspects of store location and rent within shopping centers. An understanding of such location behavior within the mall, though, helps achieving design efficiency through area allocation and selection of proper mix of tenant stores. Studies conducted on shopping centers have explored the micro-economic logic of allocation of store space and differentiation of rental amount of tenant stores in the overall spatial arrangement. Tenanting decision making is predominantly of interest to retail management researchers and has been addressed mostly through the logic of inter store externality (Pashigian \& Gould, 1998; Verdil, 2009; Vitorino, 2012) in describing differences in area allocation and rental amount. A proper tenant mix is considered responsible for economic performance of a shopping mall (Garg \& Steyn 2015; Kyriaziz \& Cloete, 2018) and is a strategic mall management decision (Marona \& Wilk, 2016). The existing policies for tenant-mix design are mostly dogmatic (Maitland, 1985), situation specific (Brown, 1999), and non-generalizable. The description of tenant stores is largely qualitative and is based on the merchandise of a store in gross terms.

While the existing policies of tenanting decision making have identified the importance of footfall of customers (Carter \& Vandell, 2005) as a driving force for maximizing sales and profits, these have not coalesced into a generalizable conceptual framework that can be applied in shopping malls for maximizing profits (YimYiu \& Xu, 2012) .

Carter \& Vandell (2005) and Sim \& Way (1989) applied the theories of geographical economics in a shopping mall and have used the bid-rent theory in explaining profit earning from a tenant store. The foot falls (gate counts) at a particular location were identified crucial in predicting sales from a store and these were explained through decreasing footfall with increasing metric distance from the central position of the mall (Carter $\&$ Vandell, 2005). This gate counts at any location is generated by the movement through it. Movement in a built environment has been examined in detail in the fields of the architecture and urban design. Hillier et al. (1983), Hillier (1996) and Peponis \& Bafna (2003) asserted that, movement depends on the accessibility of a particular location which in turn is influenced by configuration of the spatial structure and is measured through syntactic properties. Distance is a geographical property of space. This property of space has already been acknowledged in retail management studies as a factor behind foot fall. But architectural logic suggests the supremacy of topographical property of space and concludes that Archimedeanor the metric distance cannot reflect the complete configurational characteristics of a space. Therefore it will not be suitable for prediction of gate counts. Space syntax is a configurational model of space which quantifies configuration and relates it with other measurable variables like movement or gate counts. Research conducted in the field of architecture as well as in urban design suggests the supremacy of space syntax measures (integration) (Hillier et al., 
1983; Hillier, 1996; Peponis \& Bafna, 2003) over others, in describing and predicting movement within an urban area as well as in buildings.

The research results on indoor movement from retail management viewpoint have neither explored the potential of spatial configuration nor have employed the space syntax measures in a shopping mall for developing a tenant-mix decision framework. This research can bridge the gap between architectural wisdom and retail management practices through designing a tenant-mix framework design relying on the logic of space syntax.

\section{Research Methodology}

The purpose of this research is to recognize the importance of space syntax measures over normal metric measures in explaining configuration and to establish a spatial rationale behind tenanting decision making. Separate methodologies have been adopted to meet the two research objectives. The geometry of retail layouts has been analyzed for establishing the importance of space syntax method and the bidrent analysis is resorted to for establishing the spatial rationale behind tenanting decision making.

\subsection{Analysis of Retail Plan Geometry}

The verbal description of spatial configuration makes it difficult for establishing correlation with measurable behavioral variables like footfall. Space syntax methodology provides an evidence based approach in quantifying configuration.

The description of space can be done in three geometric approaches:

a) Linearity: Normal human movement follows a linear pattern. The spatial configuration can be broken down into a combination of the potential movement lines. This representation of potential movement lines is called axial lines. This abstraction is one dimensional.

b) Convex space: for a two dimensional abstraction of space, convex spaces are used. They are smallest number of polygonal spaces, which area mutually exclusive and collectively exhaustive.

c) Isovist: This is a dimensionless abstraction of space and depends on visibility of every point in space. In this paper this abstraction is not used in analysing spaces.

So, the spatial configuration can be decomposed into a map depending on the type of geometrical abstraction. The map is converted into a graph by representing corresponding convex spaces or axial lines by circles (nodes) and the connection of a node with neighbouring nodes by lines. The distance between nodes is essentially topological (number of turns) and not metric. Depth represents the number of turns to reach from one node to the other. The interrelationship between nodes is represented by the integration measure. This is a clear unambiguous description of configuration. For analysis of retail plan geometry, the layouts show interior public spaces without considering interior spaces of tenant stores. The Justified Access Graph analysis is done with AGRAPH spatial network analysis software tool.

\subsection{Bid-Rent Analysis}

The development of bid-rent approach stem from the logic of urban geography and central place theory and applied in a shopping mall because a shopping mall is an abstraction of urban area in a closed environment and customers in a shopping mall prefer stores that can be easily accessible (Carter $\&$ Vandell, 2005). From the logic of bid rent, tenant stores in a mall try to maximize their profit like firms in a city. The profit function of a tenant store can be conceptualized from the profit function of a firm in a city, by subtracting cost and rent from the volume of business. The function is finetuned with variables pertaining to the tenant stores and solved under conditions of maximization of profit and perfect competition.

\section{Analysis}

\subsection{Analysis of Retail Plan Geometry}

Gross Leasable Area (GLA) is generally used to describe shopping malls without considering their configurational differences. Four distinct typologies are identified (Verdil, 2009) as predominant shopping layouts. The typologies are based on their arrangement of circulation axis. In case of Cartesian or grid arrangements, major and minor circulation axes cross each other forming islands in between. The dumbbell system has a predominantly strong central axis. The anchors are placed, mainly, at each end of the central axis. Secondary circulation axes are present in this typology but are mostly insignificant. Branch or tree system is also characterized by a strong central axis 
with branching of secondary circulation axes. Hybrid system, as the name suggests, is characterized by the presence of characteristics of two or more typologies. The illustrative layouts of these typologies (containing characteristic features explained above) are shown in the Fig. 1.

Prevalent system of spatial description cannot express the configurational differences of the typologies. So, geometry of retail plans are analysed on layouts representing each typology drawn with equal GLA and circulation area. The interior public space is decomposed into convex spaces and axial lines through a methodology of shape recognition for all the typologies and finally the graph mathematical analysis (justified access graph) is done for convex maps using AGRAPH spatial network analysis software.
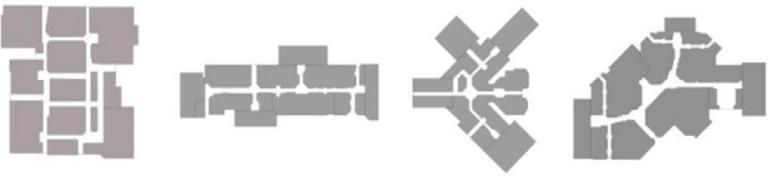

Figure 1: Representative layouts of shopping mall typologies, cartesian, dumbbell, tree and hybrid type layout (from left).

The convex and axial maps of the typologies are shown in the following Fig. 2 and the results are summarized in Table 1.

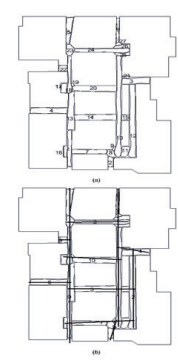

(1)

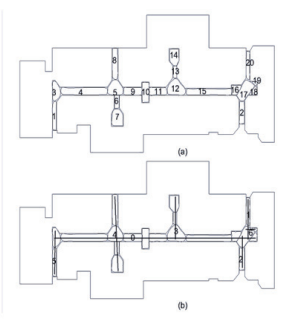

(2)

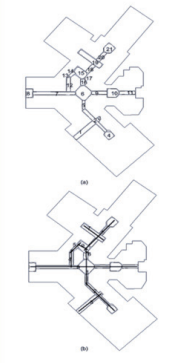

(3)

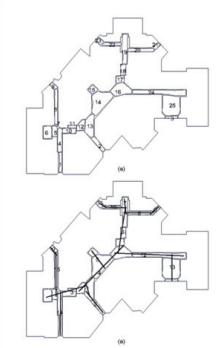

(4)
Figure 2: Convex and axial map of (1) Cartesian, (2) Dumbbell, (3) Tree, (4) Hybrid typologies.
Table 1: Summary of the convex and axial maps of the typologies.

\begin{tabular}{|l|l|l|l|l|}
\hline & Cartesian & Dumbbell & Tree & Hybrid \\
\hline $\begin{array}{l}\text { Total } \\
\text { leasable Area }\end{array}$ & 60000 & 60000 & 60000 & 60000 \\
\hline $\begin{array}{l}\text { Convex } \\
\text { Space }\end{array}$ & 27 & 20 & 21 & 25 \\
\hline Axial Line & 11 & 7 & 10 & 16 \\
\hline $\begin{array}{l}\text { Convex } \\
\text { Axial ratio }\end{array}$ & $2.455: 1$ & $2.857: 1$ & $2.100: 1$ & $1.563: 1$ \\
\hline $\begin{array}{l}\text { Net leasable } \\
\text { Area per } \\
\text { Convex } \\
\text { Space }\end{array}$ & 2222.22 & 3000.00 & 2857.14 & 2400.00 \\
\hline $\begin{array}{l}\text { Net leasable } \\
\text { Area per } \\
\text { Axial Line }\end{array}$ & 5454.55 & 8571.43 & 6000.00 & 3750.00 \\
\hline
\end{tabular}

From the results as summarized in Table 1 , the Cartesian system of arrangement is most localized (low value of net leasable area per convex space) and the dumbbell system is least localized (highest value of the same ratio). Hybrid and tree falls in between. This ratio represents the essence of the configuration differences, though all of them are comparable in terms of GLA. Similarly, from the ratio of net leasable area per axial line suggests that the dumbbell system is easiest to explore.

The graph mathematical approach (Justified Access Graph analysis) is applied for convex maps to identify the depth (topological) and integration of all the convex spaces. The mean values of all the measures are summarised in Table 2 and the network analysis is shown in Fig. 3.
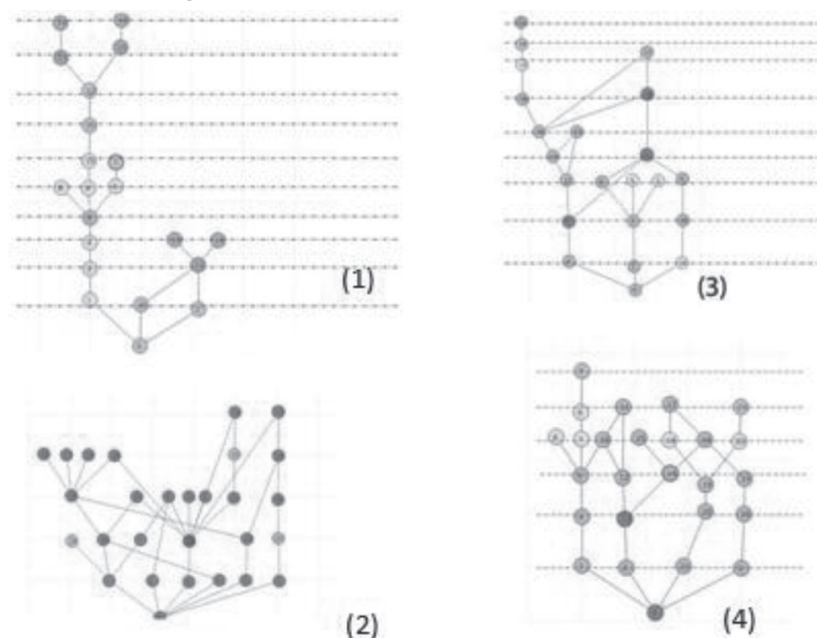

(2)

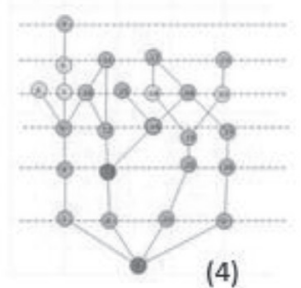

Figure 3: Justified graph of typologies, (1) Cartesian, (2) Dumbbell, (3) Tree, (4) Hybrid. 
Table 2: Summary of the average values of measures of the Justified Access Graph (JAG) analysis of typologies.

\begin{tabular}{|l|l|l|l|}
\hline & Total Depth & Mean depth & Integration \\
\hline Grid System & 108.76 & 5.43 & 2.28 \\
\hline Dumbbell system & 80.64 & 2.98 & 6.87 \\
\hline Tree System & 80.09 & 3.81 & 3.83 \\
\hline Hybrid System & 108.15 & 4.32 & 3.80 \\
\hline
\end{tabular}

* The higher the value, the more the space is integrated with the entire spatial arrangement and vice-versa

** The values are generated analyzing *jpg layouts of internal public spaces of the typologies using AGRAPH spatial network analysis software tool

From Table 2 it is found that, average integration value of dumbbell layout is highest and it is lowest for the Cartesian type arrangement. These findings also support the findings summarized in Table 1. The shopping mall layouts are similar in terms of GLA but are dissimilar in terms of syntactic measures. Not only this but this measures also reflect the configurational logic of the typologies.

\subsection{Bid-Rent Analysis}

Finding the basis for calculating a proper rent of a shop is always very crucial for a shopping mall, so framing a proper bid-rent equation is the most useful practical implication of this syntactical analysis of space. Studies on retail have paid little attention to the microlevel spatial aspects of store location and rent within shopping centers. An understanding of such location behavior within the mall, though, can help optimizing tenanting decision making.

The bid-rent function of any tenant store $\mathrm{i}$ in a shopping mall, when the mall contains $n$ number of stores, can be expressed by the following variables pertaining to tenant stores:

$\mathrm{p}_{\mathrm{i}}=$ Average price per unit of goods sold for store $\mathrm{i}$

$\mathrm{a}_{\mathrm{i}}=$ Quantity of goods sold per customer visit of that store

$A i=$ Area of store $\mathrm{i}$

$f(A i)=$ Proportion of customer traffic per unit of store area, who purchases

$\mathrm{g}_{\mathrm{i}}=$ Gate counts or foot fall at store $\mathrm{i}$

$\mathrm{r}_{\mathrm{i}}=$ Rent per unit area

$\mathrm{CF}_{\mathrm{i}}=$ Fixed cost of the store

$\mathrm{CO}_{\mathrm{i}}=$ Operating Cost of the store that depends on quantity of goods sold
$\mathrm{CM}_{\mathrm{i}}=$ Maintenance cost of the store that depends on the store area

$\mathrm{K}_{1 \mathrm{i}}=$ Conversion constant

$\mathrm{K}_{2 \mathrm{i}}=$ Area elasticity of demand constant

The profit from a tenant store can be developed from the standard bid-rent model and expanded with tenant store specific variables as mentioned earlier. The profit function can be expressed by suppressing the subscripts as:

$$
\begin{aligned}
\pi & =p \cdot a \cdot K_{1} \cdot A^{K_{2}} \cdot g^{K_{3}} \\
& -\left[C O \cdot\left(a \cdot K_{1} \cdot A^{K_{2}} \cdot g^{K_{3}}\right)+C M \cdot A+C F\right]-r \cdot A
\end{aligned}
$$

For solving the profit function, two conditions have already been discussed, i.e., profit maximization and perfect competition. For the first consideration, the Equation 1 has to be maximized. This can be achieved by equating the first order derivative of the equation to zero.

$\frac{\mathrm{d} \pi}{\mathrm{dA}}=0$

or

$$
\begin{aligned}
& \frac{d \pi}{d A}=p \cdot a \cdot f(A) \cdot g^{K_{3}} \cdot(p-C O)-C M \\
& -r+A \cdot\left[a \cdot g^{K_{3}} \cdot \frac{d f}{d A} \cdot(p-C O)\right]=0 \\
& a \cdot g^{K_{3}} \cdot[p-C O] \cdot f(A)+A \cdot\left[a \cdot g^{K_{3}} \cdot \frac{d f}{d A} \cdot(p-C O)\right] \\
& \quad-C M-r=0 \\
& \frac{d}{d A}[f(A) \cdot A]=\frac{r+C M}{\left[a \cdot g^{K_{3}} \cdot(p-C O)\right]}
\end{aligned}
$$

$f(A) \cdot A=$, where, $0<\mathrm{K}_{2}<1$ for considering decreasing returns to scale of operations,

$$
\begin{gathered}
\frac{d}{d A}[f(A) \cdot A]=K_{1} \cdot K_{2} \cdot A^{K_{2}-1}=\frac{r+C M}{\left[a \cdot g^{K_{3}} \cdot(p-C O)\right]} \\
A=\frac{r+C M}{\left[a \cdot g^{K_{3}} \cdot(p-C O) \cdot K_{1} \cdot K_{2}\right]}{ }^{\frac{1}{K_{2}-1}}
\end{gathered}
$$

Secondly, for perfect competition $\pi=0$ should be considered as excess profit by a store is bid away by others through increase in rent.

$$
r=a \cdot f(A) \cdot g^{K_{3}} \cdot(p-C O)-C M-\frac{C F}{A}
$$


Putting the value of r) in Equation (2):

$$
\begin{aligned}
K_{1} \cdot K_{2} \cdot A^{K_{2}-1} & =\frac{C M+a \cdot f(A) \cdot g^{K_{3}} \cdot(p-C O)-C M-\frac{C F}{A}}{a \cdot g^{K_{3}} \cdot(p-C O)} \\
\Rightarrow A^{*} & =\left[\frac{C F}{a \cdot g^{K_{3}} \cdot(p-C O) \cdot K_{1} \cdot\left(1-K_{2}\right)}\right]^{\frac{1}{k_{2}}}
\end{aligned}
$$

Where, $A^{*}$ is the optimal area of a store.

Optimal rent per unit area can be found out from the Equations (3) and (4):

$$
\begin{gathered}
r^{*}=C F \cdot \frac{K_{2}}{1-K_{2}} \cdot\left[a \cdot g^{K_{3}} \cdot(p-C O) \cdot K_{1} \cdot\left(1-K_{2}\right) / C F\right]^{\frac{1}{K_{2}}}-C M \\
=C F \cdot\left[K_{2} /\left(1-K_{2}\right)\right] / A^{*}-C M
\end{gathered}
$$

Where, $\mathrm{r}^{*}$ is the optimal rent per unit area of store $\mathrm{i}$.

Total revenue from a tenant store can be calculated as Equation (6) by multiplying from Equation (4) with Equation (5)

A.r; From Equation (4) and (5)

$$
\begin{aligned}
A . r & =\left[\frac{C F}{a \cdot g^{K_{3}} \cdot(p-C O) \cdot K_{1} \cdot\left(1-K_{2}\right)}\right]^{\frac{1}{K_{2}}} \\
& \cdot\left[\left(a \cdot g^{K_{3}} \cdot(p-C O) \cdot K_{1} \cdot \frac{1-K_{2}}{C F}\right)^{\frac{1}{K_{2}}}\right]-C M \\
R_{e} & =C F \cdot\left(\frac{K_{2}}{1-K_{2}}\right) \\
& -C M \cdot\left(\frac{C F}{a \cdot g^{K_{3}} \cdot(p-C O) \cdot K_{1} \cdot\left(1-K_{2}\right)}\right)^{\frac{1}{K_{2}}}
\end{aligned}
$$

From equation (6) it can be concluded that, considering the assumption of ceteris paribas or other things remaining constant, total revenue generation ability from a tenant store depends on the gate counts near it, when other tenant store specific variables remain constants. The model is based on certain assumptions like absence of inter store externalities and vertical movement. External factors controlling foot fall are also not considered.

\section{Discussion}

\subsection{Customer Density and Metric Distance from the Central Position}

Research results supported the concept that consumers prefer closest stores ceteris paribas (Carter \& Vandell,
2005). Following this logic, the stores that are most accessible than others in a particular arrangement will attract more customer foot fall when all other factors remain unchanged.

The gate counts is dependent on the metric distance from the center of the entire spatial arrangement, so, gate counts can be explained through the metric distance: i.e., $\mathrm{g}=\mathrm{f}(\mathrm{t})$, where $\mathrm{dg} / \mathrm{dt}<0$ (where $\mathrm{t}$ is the metric distance from central location of the mall.)

Considering the linear symmetric spatial arrangement, as mentioned at the time of describing the model, the gate counts is maximum at $\mathrm{t}=0$ or at the center and decreases with increasing distance. There is a significant evidence that $\mathrm{f}(\mathrm{t})$ is downward sloping (Carter \& Vandell, 2005). The slope of $\mathrm{f}(\mathrm{t})$ can vary depending upon various other non-spatial factors but it will slope downward nevertheless. So, metric distance is one important factor for determining customer density and therefore retail rents.

But, the idealistic situation of symmetrical mall will is not possible always and there can be difference of density at equal distances from the shopping mall center. So, some other variable for analyzing gate counts or foot fall is required.

\subsection{Customer Density and Integration Value:}

The link between integration value and human movement has been investigated in space syntax researches. These researches suggested that integration value captures how people cognitively perceive a space (Hillier et al., 1983; Hillier, 1996 and Peponis \& Bafna, 2003). So, it is not only metric distance that governs foot fall but also integration values at a particular convex space. Gate counts can therefore be expressed as a function of integration value, $\mathrm{i}$

$g=f(i)$, where $d g / d i>0$

It can therefore, be concluded that the gate counts can be expressed as a function of distance and integration value, or

$\mathrm{g}=\mathrm{f}(\mathrm{t}, \mathrm{i})$ where $\mathrm{dg} / \mathrm{di}>0$ and $\mathrm{dg} / \mathrm{dt}<0$

Substituting this functional form in Equation 6, it reveals that, revenue generated from a tenant store can be explained as a function of metric distance from center of the mall and the integration value. 
Or,

$\mathrm{R}_{\mathrm{e}}=\mathrm{f}(\mathrm{t}, \mathrm{i})$ where $\mathrm{dRe} / \mathrm{di}>0$ and $\mathrm{dRe} / \mathrm{dt}<0$

\section{Conclusions}

As, the gate counts depend both on metric and nonmetric property of a particular space and as the total revenue from a store is dependent on gate counts, it can be concluded from the Equation 6 that, when other things remain constant, total revenue decreases with increasing distance from the center and increases with higher integration value depending on the logic that, the value of gate counts is directly proportional to the integration value and inversely proportional to the metric distance from the center of the mall.

The essence of the discussion can be encapsulated in the following 2X2 grid (Fig. 4) for ease in decision making. The scatter plot of the metric distances of every convex space and their integration values help in development of this model. Here, integration value is shown in the vertical axis and distance from the center is shown in the horizontal axis.

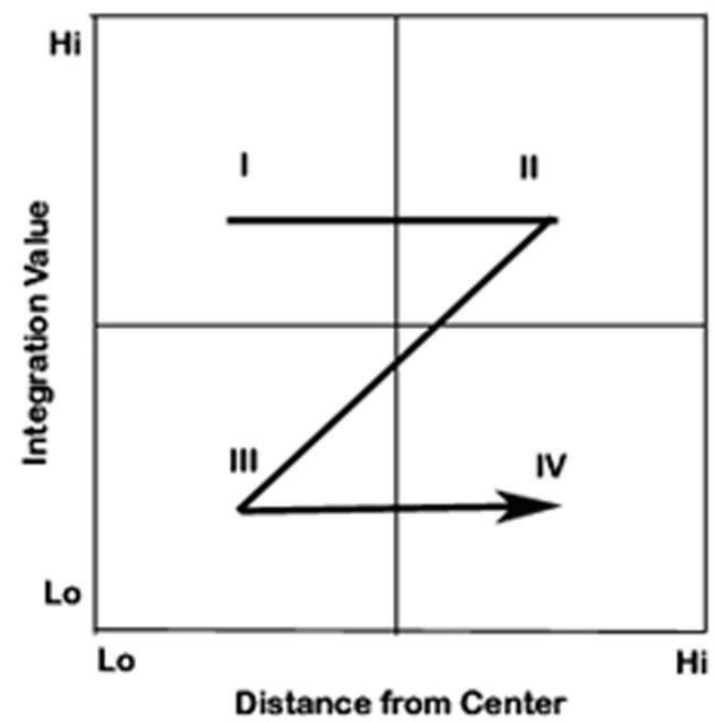

Figure 4: Strategic decision making model for shopping malls.

In this 4 cell model, the first cell accommodates the convex spaces with high integration value and low distance from the center and therefore the stores around these convex spaces enjoy maximum rent per unit area of store. It is the area in the overall spatial arrangement that is most accessible and therefore enjoys maximum customer foot fall or gate counts.
The optimal areas of the stores are also least for these stores. The second cell characterizes of high integration value and high distance from the center, whereas, the third cell characterizes of low integration value and low distance from the central area in the spatial configuration. As, non-metric parameters (integration) are more influential than metric distance (Sadalla $\&$ Staplin, 1980), the rent of stores will be higher around convex spaces in cell number 2 than those in cell number 3 . The cell number four will house convex spaces with lowest integration value and highest distance from the center, therefore least accessible with minimum customer foot fall. The stores around these convex spaces will be of highest leasable area and can contribute lowest rental. This area is potential for locating attractors. The integration value can thus be utilized alongside the metric distance from the center in formulating a tenanting decision making strategy.

A framework for economic decision making is therefore possible relying on spatial configurational variables (metric distance and integration value). This framework can operate both from conservative and generative perspectives. The configurational characteristics can be conserved through identifying best-fit stores for that location. On the other hand design correction strategies can be generated for better functionality. For example, additional entry points can be included near cell II (high distance from the centre and high integration value) and signages can be considered at Cell III. This framework can also help evaluate among alternative design proposals.

\section{References}

Brown, G. (1999). Design and value: Spatial form and the economic failure of a mall. Journal of Real Estate Research, 17(2), 189-225.

Carter, C. C., and Allen, M. T. (2012). A method for determining optimal tenant mix (including location) in shopping centers. Cornell Real Estate Review, 10(1), 72-85.

Carter, C., and Vandell, K. (2005). Store location in shopping centers: Theory and estimates. Journal of Real Estate Research, 27(3), 237-266.

Garg, A. K., and Steyn, S. (2015). The Ideal Tenant Mix and Shopping Centre Size for the Proposed Thatchfield Convenience Centre. International Journal of Business and Management, 10(1), 243-257.

https://doi.org/10.5539/ijbm.v10n1p243 
Hillier, B. (1996). Cities as movement economies. Urban Design International, 1(1), 41-60. https://doi.org/10.1057/udi.1996.5

Hillier, B., and Leaman, A. (1976). Architecture as a discipline. Journal of Architectural Research, 5(1), 28-32.

Hillier, B., Hanson, J., Peponis, J., Hudson, J., and Burdett, R. (1983). Space syntax, A Different urban perspective. Architect's Journal, 178, 47-63.

Kyriaziz, A. N., and Cloete, C. E. (2018). Tenant mix in shopping centres: South Africa and the United Kingdom compared, Journal of Business and Retail Management Research, 12(2), 152-162.

https://doi.org/10.24052/JBRMR/V12IS02/ TMISCSAATUKC

Maitland, B. (1985). Shopping malls: planning and design. Nichols Pub Co.

Marona, B., and Wilk, A. (2016). Tenant mix structure in shopping centres: some empirical analyses from Poland. Entrepreneurial Business and Economics Review, 4(2), 51-65. https://doi.org/10.15678/EBER.2016.040205

Pashigian, B. P., and Gould, E. D. (1998). Internalizing externalities: the pricing of space in shopping malls. The Journal of Law and Economics, 41(1), 115-142. https://doi.org/10.1086/467386

Peponis, J., Karadima, C., \& Bafna, S. (2003). On the formulation of spatial meaning in architectural design. In Proceedings to the 4th International Space Syntax Symposium.

Piatkowska, K. K. (2012). Economy and architecture. The role of architecture in process of building the economic potential of space, Humanities and Social Sciences Review, 1(2), 549-555.
Roulac, S. (1996). Real estate market cycles, transformation forces and structural change. Journal of Real Estate Portfolio Management, 2(1), 1-17.

Sadalla, E. K. and Staplin, L. J. (1980). The perception of traversed distance, interactions. Environment and Behaviour, 12, 167-182. https://doi.org/10.1177/0013916580122003

Sim, L. and Way, C. (1989). Tenant placement in a Singapore shopping centre. International Journal of Retailing, 4, 4-16. https://doi.org/10.1108/EUM0000000002920

Vandell, K. D. \& Lane, J. S. (1989). The economics of architecture and urban design: some preliminary findings. Real Estate Economics, 17(2), 235-260. https://doi.org/10.1111/1540-6229.00489

Verdil, A. (2009). Transformation of Space Behaviour Relation: A Case Study of Shopping Centres in Istanbul. In Proceedings of 7 th International Space Syntax Symposium in KTH, Stockholm.

Vitorino, M. A. (2012). Empirical entry games with complementarities: An application to the shopping center industry. Journal of Marketing Research, 49(2), 175-191. https://doi.org/10.1509/jmr.10.0021

Voordt, D. J. M. Van der. \& Vrielink, D. (1987). Kostenkwaliteit van wijkwelzijnsaccommodaties.

YimYiu, C., \& Xu, S. Y. (2012). A tenant-mix model for shopping malls. European Journal of Marketing, 46(3/4), 524-541.

https://doi.org/10.1108/03090561211202594 


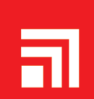 \\ CHITKARA}

\section{Creative Space}

Chitkara University, Saraswati Kendra, SCO 160-161, Sector 9-C, Chandigarh, 160009, India

Volume 7, Issue 2

January 2020

ISSN 2321-3892

Copyright: [C 2020 Sumanta Deb and Keya Mitra] This is an Open Access article published in Creative Space (Creat. Sp.) by Chitkara University Publications. It is published with a Creative Commons Attribution- CC-BY 4.0 International License. This license permits unrestricted use, distribution, and reproduction in any medium, provided the original author and source are credited. 